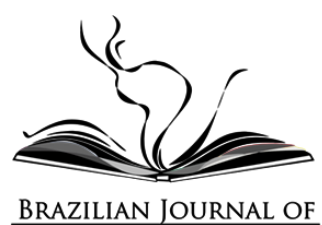

\title{
A BASE ESPACIAL CHINESA EM NEUQUÉN, ARGENTINA
}

\author{
LA ESTACIÓN ESPACIAL CHINA EN NEUQUÉN, ARGENTINA \\ CHINA'S SPACE BASE IN NEUQUÉN, ARGENTINA
}

Rogério do Nascimento Carvalho? (iD

Universidade de São Paulo, Brasil

\begin{abstract}
Resumo: $O$ objetivo do artigo é caracterizar a aproximação da República Popular da China a países da América Latina, neste caso à Argentina, tendo em vista a construção de estação espacial na província de Neuquén. Também tem o intuito de demonstrar fatores que levam a esta aproximação, pois a China foi responsável por auxiliar a economia argentina no momento em que esta passava por grave crise de credibilidade. A abordagem adotada é a de narrativa de fatos, complementada com dados exarados por documentos conjuntos e, ainda, extraídos de artigos científicos e reportagens recentes, abordando a forma como a China reverbera o soft power e começa a exercer influência na região. Coaduna-se também com o espírito chinês de cooperação e analisa-se como são na prática os acordos e compromissos assumidos. A conclusão dos documentos analisados permite depreender que a vontade chinesa em promover auxílio a países como a Argentina pode viabilizar uma etapa de prosperidade, sempre que os países tomem a devida atenção, já que a expansão chinesa se mostra pujante e, portanto, impossível de acompanhar para nações que não possuem a infraestrutura necessária, o que os levaria a depender cada vez mais das benesses chinesas.
\end{abstract}

Palavras-chave: América Latina; Argentina; China; Base Espacial; Soft power.

Resumen: El objetivo del artículo es caracterizar la aproximación de la República Popular China a países latinoamericanos, en este caso a Argentina, con miras a construir una estación de espacio lejano en la provincia de Neuquén. También se busca demostrar los factores que conducen a tal aproximación, ya que China se responsabilizó por ayudar a

\footnotetext{
' Doutorando no Programa de Pós-graduação Interunidades de Integração da América Latina (PROLAM) da Universidade de São Paulo (USP), Mestre em Estratégia Marítima pela Escola de Guerra Naval (EGN), Pesquisador no Grupo sobre Genocídios e Conflitos Armados da Universidade Federal de São Paulo - Campus Osasco. Professor universitário e advogado. E-mail: rogerionascimento@usp.br
} 
la economía argentina en un momento en que este país atravesaba por una grave crisis de credibilidad. El enfoque adoptado es el de narrativa de hechos, complementado con datos elaborados por documentos conjuntos y también extraídos de artículos científicos e informes recientes, que tratan del modo como China refleja el soft power y comienza a ejercer influencia en la región. El artículo refleja también el espíritu de cooperación del país chino y analiza cómo son en la práctica los acuerdos y compromisos asumidos. La conclusión de los documentos analizados muestra que el deseo de China de promover cooperación a países como Argentina puede viabilizar una etapa de prosperidad, siempre y cuando los países tengan el debido cuidado, ya que la expansión de China se revela como vigorosa y, por tanto, imposible de seguir para naciones que no cuentan con la infraestructura necesaria, lo que podría llevarlas a depender cada vez más de los beneficios del país chino.

Palabras-clave: América Latina; Argentina; China; Estación espacial; Soft power.

Abstract: This article intends to characterize the approximation of the People's Republic of China to Latin American countries, especially Argentina, in view of the building a spatial base in the province of Neuquén. It also aims to demonstrate factors that lead to this approximation, since China was responsible for assisting the Argentine economy at a time when it was going through a serious credibility crisis. For this, The approach adopted is the narrative of facts, complemented with data drawn up by joint documents and also, facts that were extracted from scientific articles and recent reports, addressing the way in which China reverberates soft power and begins to exert influence in the region. It is also consistent with the Chinese spirit of cooperation and analyzes how the agreements and commitments assumed occur practice. The conclusions of the analyzed documents show that the Chinese will to promote aid to countries like Argentina can make a stage of prosperity viable. Provided that countries pay due attention, since Chinese expansion is proving to be vigorous and, therefore, impossible to be followed for nations that do not have the necessary infrastructure, which would lead them to depend more and more on Chinese benefits.

Keywords: Latin America; Argentina; China; Space base; Soft power. 


\section{Introdução}

As relações atuais da República Popular da China com os países da América Latina têm sido mais frequentes desde o fim do século XX e nos primórdios deste século, tornando-se importantes no continente (URDINEZ et al., 2016), e cada vez mais para o mundo. Tradicionalmente, como premissa oficial de sua política externa, a China busca estabelecer relações harmônicas e de benefícios mútuos com países aos quais tem parcerias econômicas e políticas.

Em contraposição à forma como os Estados Unidos se posicionam em relação à região, relegando-a a planos secundários na execução de sua política externa. Este fato faz com que a presença chinesa tenha sido mais atuante com políticas de auxílio financeiro e de investimentos na infraestrutura da região.

Neste artigo, abordamos as relações da China com a Argentina, enfatizando o acordo bilateral entre os países que permitiram a construção de estação espacial na província de Neuquén. Este acordo atende prioritariamente a interesses chineses de investigação espacial pacífica. Porém, estas negociações incomodam os EUA à medida que indispõem o desenvolvimento de sua política na região.

O debate proposto pelo presente trabalho diz respeito ao fato de que a China permeia as fímbrias e os espaços que são ocupados através de negociações e acordos internacionais. Neste caso, é imperioso ressaltar a pressão que Argentina sofria por credores internacionais devido às dificuldades em honrar o pagamento de empréstimos tomados para a manutenção da ordem econômica do país.

Desta feita, o auxílio do gigante asiático em conceder créditos com vista a realizar pagamento dos compromissos argentinos teve como contrapartida acordo para o estabelecimento de estação espacial com 
cessão de soberania no sul do país, privilegiando o interesse de Pequim na execução de sua política global.

De fato, em que pese a capacidade da China em oferecer auxílio à Argentina, se faz necessário revisitar fatos históricos relevantes no tempo presente com o intuito de entender que as relações Pequim-Buenos Aires se solidificam em nome do respeito mútuo e harmônico entre as nações. Denota-se, portanto, a dimensão que pode ser projetada no futuro, tendo em vista a confiança adquirida dos países em posicionamentos comuns compartilhados em momentos anteriores.

O argumento a ser apresentado no texto menciona a forma como China executa os ditames prescritos nos congressos do Partido Comunista. Recentemente reforça a expansão harmoniosa pelo globo, alterando, no caso da construção da estação espacial de Neuquén, a geopolítica consolidada pelos EUA na região. Justifica-se, o presente artigo em verificar a conjuntura político-econômica portenha e de como se conecta à política preconizada por Pequim.

\section{Relações sino-argentinas e aplicação da política de Pequim}

Nos últimos anos, o auxílio promovido por Pequim enriquece as relações sino-argentinas, com intuito de contribuir para a recuperação financeira do parceiro sul-americano. Todavia, esta premissa de confiança e respeito mútuo advém da sinalização que os países têm construído conjuntamente. O apoio dado pela Argentina à China em 1990 foi de grande valia, onde destacamos a viagem presidencial do então presidente Carlos Saúl Menem (1989-1999) à Pequim, sendo o primeiro chefe de Estado latino-americano a realizar visita oficial após os incidentes ocorridos em 4 de junho de 1989 em 天安门广场 (Tiān'ānmén Guăngchăng)² (SHIXUE, 2006, p. 68).

\footnotetext{
${ }^{2}$ Praça da Paz Celestial (tradução nossa).
} 
Desta feita, China (2010) ilustra que o encontro dos chefes de Estado culminou na adoção de declaração final onde se menciona textualmente o apoio de Pequim a Buenos Aires na questão da reivindicação do arquipélago das Malvinas. Em troca, o apoio argentino à reunificação de Taiwan à China continental sinalizou uma sintonia entre as nações em temas sensíveis de alta complexidade territorial regional, o que é corroborado por Ellis (2014) e que demandam apoio junto à comunidade internacional pela realização de negociações sob os ditames das resoluções já expostas da Organização das Nações Unidas ${ }^{3}$. Referido apoio se encontra renovado nas palavras de Zou $\mathrm{Xiaoli}^{4}$, no último dia 23 de dezembro de 2020 em reunião bilateral com Daniel Filmus ${ }^{5}$, na qual reitera o apoio de Pequim à posição argentina na questão Malvinas (ARGENTINA, 2020b).

Como é cediço, a Argentina, após o período da ditadura militar (1976-1983) e sobretudo pelo evento Guerra das Malvinas (1982), mergulhou numa situação de debilidade econômica que não foi resolvida no primeiro governo democraticamente eleito de Raúl Alfonsín (1983-1989). Restou ao sucessor, Carlos Saúl Menem (1989-1999) a elaboração de um plano econômico que, mediante um processo de paridade rígida do peso argentino à moeda norte-americana, levou o país à estabilização econômica temporária.

Porém, como as economias não são assimétricas, evidentes pressões inflacionárias e estruturais abateram os portenhos que adentraram em um novo ciclo conturbado no setor econômico-financeiro, o que trouxe instabilidade política ao país e até mesmo a renúncia do presidente Fernando de La Rúa (1999-2001), em 2001.

\footnotetext{
${ }^{3}$ Resolução 2065 (XX), da Assembleia Geral de 16 de dezembro de 1965, que reconhece a existência de disputa de soberania no arquipélago Malvinas e conclama aos países (Argentina e Reino Unido) a sentarem à mesa de negociações.

Com o agravamento da tensão nas Malvinas e a retomada do arquipélago pela Argentina, o Reino Unido convocou o Conselho de Segurança e, no espaço de um dia após a retomada, o Conselho já se manifestava através da Resolução 502 do Conselho de Segurança, datado de 03 de abril de 1982 e conclamava à Argentina pelo fim imediato das hostilidades (CARVALHO, 2017).

4 Embaixador plenipotenciário da República Popular da China em Buenos Aires (atual).

${ }^{5}$ Secretário de Malvinas, Antártida e Atlântico Sul do Ministério das Relações Exteriores, Comércio Internacional e Culto da República Argentina (atual).
} 
Van de Maele (2017) menciona que durante o mandato do presidente chinês Hu Jintao (2003 -2013), a China assume explicitamente o soft power ${ }^{6}$ nas relações internacionais com o globo e, na América Latina, inicia ações de fulcro político, econômico, cultural e de cooperação militar com os países da região, bem como estabelece vínculos de amizade por meio da instalação de Institutos Confúcio ${ }^{7}$ nas Universidades de Buenos Aires, La Plata e de Córdoba, na Argentina (HANBAN, 2019).

Nada obstante, é no período conhecido como era Kirchner ${ }^{8}$ (2003-2015) que a aproximação entre Argentina e China ganhará patamar diferenciado de "ampla parceria estratégica" (CHINA, 2010; WILSON, 2015), segundo a qual, o aprofundamento das relações bilaterais entre as nações amigas converge a ambiente propício como base fundamental para o entendimento recíproco em horizonte de longo prazo, representado pela criação do comitê sino-argentino de cooperação em defesa, tecnologia e indústria (WILSON, 2015, p. 3). O comitê tem a responsabilidade de lançar as premissas que culmina em projetos de fôlego, dos quais a estação espacial chinesa de Neuquén é um de seus produtos (FIGURA 1).

\footnotetext{
${ }^{6}$ Entender o soft power como influência política de uma nação para facilitar a composição entre nações soberanas e fazer com que a outra nação possa aderir a sua esfera de influência desde que obtenha privilégios ou resultados positivos que possam justificar a aproximação (BONIFACE, 2016).

${ }^{7}$ Instituição de ensino sem vínculo de lucro do governo chinês que visa estabelecer laços com países para conhecimento da língua e cultura chinesa (HANBAN, 2019).

8 Também conhecido como era K ou Kirchnerismo, engloba os mandatos presidenciais de Néstor Kirchner (2003-2007) e de Cristina Elisabet Fernández de Kirchner(2007-2015) da República Argentina.
} 
Figura 1 - Localização da estação espacial

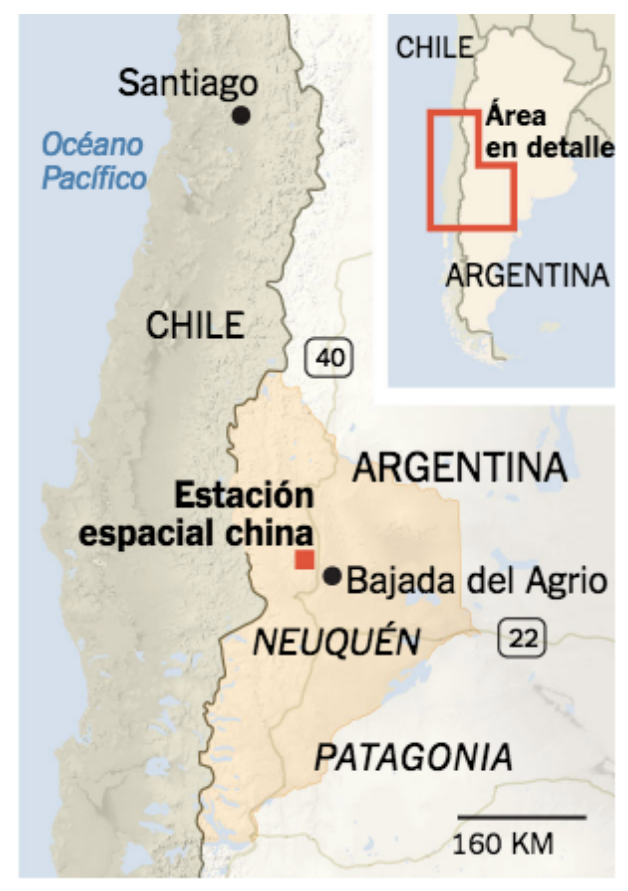

Fonte: Londoño (2018).

Acordos foram firmados entre as nações, em reuniões bilaterais, em que se destaca o interesse chinês no setor produtivo argentino, tendo em vista suas necessidades internas. Segundo Gomes Júnior (2016) estes conceitos foram construídos por vínculos comerciais desde o século XX, O que levou à então presidente argentina, Cristina Fernández de Kirchner (2007-2015), a avaliar positivamente as ações protagonizadas por Pequim visando o desenvolvimento da sociedade portenha (CHINA, 2010). Ainda segundo a ex-presidente, a Argentina não deveria temer a entrada do gigante asiático, pois em pouco este país alçaria o posto de principal ator do globo e o fato de estarem estrategicamente interligados proporcionaria a repartição de benesses, o que levaria Buenos Aires a desenvolver uma das mais fortes relações com Pequim no continente (URDINEZ et al., 2016).

Esta iniciativa chinesa só se tornou possível pelo histórico de relações internacionais entre os dois países, bem como pela sensação de vazio deixado pelos EUA na região. É cediço que as últimas administrações norte-americanas não reservaram espaço privilegiado à América Latina. Portanto, o descuido das fímbrias de espaços na região permite a 
ocupação por Pequim, que utiliza da política de cooperação e aproximação, também conhecida como "poder de atração" (ARANDA; VAN DE MAELE, 2013, p. 500) - mediante investimentos como meio de persuasão e obtenção de apoio dos países com quem efetua acordos. Com isso, a China promove a retórica do discurso da integração Sul-Sul, com intuito de desafiar os interesses relegados pelos EUA na região (URDINEZ et al., 2016; SHIXUE, 2006, p. 76).

Jaffe (2018) aduz que a China constrói a parceria com a Argentina entendendo as dificuldades financeiras e a evasão de divisas. Por isso, está ciente da necessidade de injetar recursos com intuito de aliviar a pressão do peso argentino, visando menor turbulência e garantia de melhores índices de confiança ao país. Utiliza-se, para tanto, contratos de swap cambial da ordem de USD 10.200 bilhões (FREITAS, 2016, p.18) subsidiados por Pequim ${ }^{9}$ e válidos por 3 anos, a contar de julho de 2014 (WILSON, 2015, p. 11). A liberação de USD 11 bilhões para infraestrutura hidrelétrica e modernização de linha férrea argentina (PARELLO-PLESNER, 2016). Como contrapartida, iniciaram-se entendimentos para o acordo conjunto de construção de estação espacial chinesa localizada em Bajada del Agrio, na patagônia argnetina, a ser denominada CLTC-CONAE-NEUQUEN ${ }^{10}$, em regime de comodato por período de 50 (cinquenta) anos e supervisionada pela Entidade Nacional de Comunicações, do Ministério da Modernização da República Argentina.

O argumento chinês repousa na situação interna argentina de volatilidade econômica e do não auxílio dos EUA. Neste ínterim, o aproveitamento do histórico das relações entre os países facilita o entendimento dos interesses que cada parte buscava em relação ao outro. Neste cenário, a Argentina não se oporia à presença chinesa em seu território, concedendo-lhe privilégios para ter acesso à cooperação

\footnotetext{
${ }^{9}$ Este recurso tem sido usado, neste caso, para adquirir bens chineses ou argentinos. É um exemplo da iniciativa chinesa de financiar países em desenvolvimento de modo a induzi-los a adquirir seus produtos. Evidentemente, o acordo na verdade é de mão única, pois coloca a Argentina, com as combalidas reservas de seu Banco Central, em situação de dependência, pois acaba, em parte, por financiar importações chinesas (FREITAS, 2016, p. 18).

10 CLTC (China Satellite Launch and Tracking Control General); CONAE (Comisión Nacional de Actividades Espaciales da República Argentina).
} 
protagonizada por Pequim. As negociações exigiam atuação firme no sentido de acalmar o mercado e passar mensagem aos credores de títulos argentinos de que a nação teria condições de honrar com seus compromissos e, assim, encontrar sobrevida no mundo globalizado.

A celeuma da política protagonizada por Pequim mostra-se complexa, porém de visualização cristalina. O exercício de poder que a China encontra na América Latina está calcado na dificuldade que os países da região, neste caso a Argentina, têm em encontrar saídas para a dependência de exportação de commodities e sua alta volatilidade no mercado internacional. O sucesso ou fracasso de política destes países depende sobremaneira do humor dos principais atores globais que varia e faz embalar os preços dos principais ativos dos países da América Latina. Portanto, os países dependentes ficam reféns da determinação de preços imposta por grupos econômicos poderosos e pelas decisões das nações que influenciam os destinos do globo.

No que concerne à Argentina e, a partir da era Kirchner, o fato de haver intermediação com a China é a oportunidade vista pelos dirigentes para passar à população a imagem de que a nação estaria em rumo de progresso, pois as intenções firmadas pelos dois países preconizam a política do ganha-ganha com viés de cooperação e, portanto, diante da postura oficial não haveria nenhum óbice na concessão de área para construção da estação espacial chinesa em território argentino.

E, diferentemente das ações realizadas pela China nos demais países da América Latina, na Argentina o âmago se mostra mais profundo, tendo em vista que a cooperação capitaneada por Pequim envolveu transferência de soberania territorial, praticamente a criação de um enclave a fim de atender interesses chineses, visando a sua expansão que também é sentida em outros continentes do globo. 
Dessa forma, considerando a hipótese expansionista e de presença chinesa no globo e, em especial, na Argentina, assistimos à possibilidade de estar se consolidando a interferência do poder chinês na condução dos destinos de uma nação, no caso da Argentina. Nesta conjuntura, a estratégia chinesa é assertiva no sentido de proporcionar benefícios imediatos ao país que necessita de auxílio, porém, a contrapartida pode se tornar um ônus pesado para a Argentina, visto que a cessão de soberania em seu território, com concessão de benefícios em largo prazo, pode trazer consequências nas relações com os demais países, acossados pela possibilidade do resultado do expansionismo chinês na região.

E, para provar que a preocupação das demais nações não é objeto de mera especulação, estudos protagonizados por Van de Maele (2017) indicam que o acordo celebrado entre China e Argentina pode atingir até USD 1 bilhão que envolvem investimentos militares, como venda ao governo de Buenos Aires de aeronaves, navios, tanques anfíbios e principalmente o intercâmbio militar entre as forças armadas das duas nações, bem como a cooperação estratégico-espacial que é objeto deste artigo.

E, se já não bastasse a entrada da China na América Latina com seu projeto de poder, em especial a construção da estação espacial na Argentina, Jaffe (2018) indica que houve alteração do paradigma até então existente representado pelo domínio dos EUA na região, pois hodiernamente esse país entende que historicamente a América Latina pertence a sua área de influência. Mesmo com a advertência que Costa (2016) preconiza, que o país norte-americano deverá se adaptar para a transição ao sistema multipolar, dada a complexidade e "a crescente tendência dos Estados-nações de fortalecerem-se com base no sucesso econômico e no comércio internacional" (COSTA, 2016, p. 327). Tal é justamente o ponto que a política chinesa opera na Argentina com vistas a desenvolver a cadeia produtiva de insumos (CHINA, 2018). 
Para Wilson (2015) a aproximação dos países da América Latina com a China, e em especial da Argentina, impacta os interesses norte-americanos na região, pois os Estados Unidos assistem à confrontação dos pilares representados pela secular política da "doutrina Monroe"11. Segundo o autor, para poderem ainda exercer influência na região, os EUA deveriam liderar a promoção de políticas que visem a prosperidade, a segurança, a democracia e o desenvolvimento da América Latina a partir de programas de parceria e igualdade.

A preocupação atual da China na América Latina é de criar uma rede de países que possa contribuir de forma segura para a coleta de informações a serem manipuladas conforme seus interesses. Isso ocorre nos moldes dos EUA, que mantêm com seus aliados uma rede denominada Cinco Olhos ${ }^{12}$ (GOSWAMI, 2019), segundo a qual se estabelecem vínculos entre si, visando a defesa comum sob a égide da percepção de ameaças externas. Atualmente isto inclui a China, bem como os demais atores que os norte-americanos julgam ser seus inimigos ou países que afetam direta ou indiretamente seus interesses.

Com a assunção do presidente Xi Jinping (2013 - atual) a aplicação da política chinesa se aprofunda com a Argentina, tendo em vista a consolidação e renovação de apoio mesmo durante o governo do presidente Maurício Macri (2015-2019) que, ao ratificar o acordo celebrado por sua antecessora, aduz em protocolo adicional ao acordo que a estação espacial deverá ser de uso pacífico, rechaçando viés militar (DINATALE, 2020). Desse modo, Macri não impediu o seguimento do desenvolvimento do projeto, mesmo sendo aliado mais próximo dos EUA do que sua antecessora e seu sucessor.

\footnotetext{
$"$ A Doutrina Monroe estabelece: América para os americanos. De acordo com Costa, "na verdade, essa doutrina significava, antes de tudo, uma autêntica autoproclamação de "direitos naturais" de uma "jovem potência" que emergia do outro lado do Atlântico, para o livre exercício de sua política de expansão nessa parte do globo" (COSTA, 2016, p. 65).

12 A rede está formada pelos seguintes países: Austrália, Canadá, Nova Zelândia, Reino Unido e Estados Unidos da América (GOSWAMI, 2019).
} 
No período de seu governo, Macri firma com o presidente chinês o "Plano de Ação Conjunta (2019-2023)", que reafirma a possibilidade de manter ajuda visando a estabilidade econômica e financeira da Argentina. Isso inclui a ampliação de contratos de swap da ordem de USD 9 bilhões, visando fortalecer as reservas do Banco Central da República Argentina (BCRA), bem como abrindo a possibilidade de desenvolver parcerias que envolvam o ambicioso projeto chinês da reconstituição da antiga rota da seda, com a vertente a alcançar a América Latina (CHINA, 2018).

Recentemente, sob a presidência de Alberto Fernández (2019 atual), o acordo para a cooperação das atividades espaciais é publicado por meio da resolução 30517 de 7 de agosto de 2020 (ARGENTINA, 2020a). Dinatale (2020) sustenta que tal resolução teve influência direta do governo de Pequim com intuito de não haver questionamentos sobre os direitos expressos no acordo entre as duas nações. Em contrapartida, há liberação de novo contrato de swap entre os bancos centrais das duas nações da ordem de USD 18,5 bilhões, o que reforça as reservas internacionais portenhas, em face de alta volatilidade global, causada principalmente pela pandemia da Covid-19, muito embora na Argentina haja fatores críticos anteriores de ordem econômica que agravam o quadro.

Desta forma, a presença da China na América Latina afeta diretamente os interesses norte-americanos na região à medida que Pequim oferece vantagens concretas aos países do continente, notadamente no campo financeiro e na infraestrutura regional (CHINA, 2016), desde que seja facilitado o escoamento de produtos primários para serem exportados à China. Ou seja, o auxílio é dirigido de forma a atender também a interesses geoeconômicos dos investimentos orientais em suas demandas internas, visando garantir o consumo de seu mercado interno que demanda cada vez mais por produtos da América Latina. Esta estratégia, é corroborado pela edição do "China's Policy Paper on Latin America and the Caribbean" (CHINA, 2016), que mesmo sem fazer menção 
individualizada às nações, preconiza a continuidade da adoção do soft power chinês no continente.

Outro exemplo da aproximação chinesa com Buenos Aires se faz sentir na questão Malvinas que é suscitada por Wilson (2015). O autor afirma que os EUA se consideram neutros na reivindicação territorial, quando na verdade, em 1982, apoiaram os britânicos no conflito, selando uma aliança sólida que possui com o Reino Unido (CARVALHO, 2017). Enquanto isso, os chineses, segundo Gomes Júnior (2016), dispondo do mesmo poder de veto no seio do Conselho de Segurança das Nações Unidas, se abstiveram de votar na Resolução 502 que, a pedido do Reino Unido, exigia a retirada imediata das tropas argentinas em solo malvinense.

A China, consciente deste fato, apoia a pretensão portenha e consegue aproximar-se mais da Argentina. Entretanto, Wilson (2015) alerta que a possibilidade de a China fornecer armamentos já fez com o que o Reino Unido reorientasse sua política para a defesa e segurança do arquipélago. Levando em consideração os valores elevados dos acordos sino-argentinos, Wilson (2015) presume que no horizonte das próximas décadas as forças armadas argentinas não terão capacidade a ponto de reestabelecer um conflito armado pela soberania do território. Há de se verificar a fragilidade financeira argentina em honrar o pagamento de débitos, cujo desafio está em equacionar a via menos danosa de proceder com esta questão. Contudo, não se descarta a intensificação de protestos no sentido de reaver o território que se julga usurpado pelos britânicos em 1833 e, este fato poderá requerer uma posição dos EUA, país que ainda conta com o ressentimento dos países da América Latina pela decisão tomada em 1982. 


\section{A estação espacial chinesa na Argentina: o soft power chinês sobre o território}

Como vimos no item anterior, a China, segundo Londoño (2018), ao se aproveitar da crise financeira pela qual passam países da América Latina, como o que a Argentina viveu em 2009, enxerga uma janela de oportunidade para imprimir política perante a fragilidade representada econômica desses países. No caso da Argentina, tal vulnerabilidade é representada pelos índices altos de inflação, pela pressão sobre os preços administrados pelo governo e, ainda, pela pior seca agrícola dos últimos cinquenta anos que desestimulou a reação econômica. Diante deste quadro, acordos foram confeccionados entre os governos de Pequim e Buenos Aires que, segundo o autor, visavam sobretudo atender "ambições espaciais de Pequim" (LONDOÑO, 2018).

A Estação CLTC-CONAE-NEUQUEN, negociada em segredo, advém da iniciativa de acordos que envolvem a aquisição de armamentos que, segundo Van de Maele (2017) e Wilson (2015), representam o sinal verde para a aquiescência portenha na construção do empreendimento. Desta forma, segundo Urdinez et al. (2016), a Argentina torna-se o país que inova nas relações com os chineses entre os demais países da América Latina, ao permitir no seio de seu território soberano obra de tamanha magnitude que foi aprovada em dezembro de 2014 pelo senado argentino, consoante ao espírito traçado na cooperação sino-argentina.

Trata-se da "mais moderna estação de pesquisa da RPC"13, e a primeira fora do país" (GOMES JUNIOR, 2016, p.63). Contudo, não há outras bases espaciais chinesas localizadas em países da América do Sul, bem como não há eventuais tratativas entre a China e outros países latino-americanos para a criação de bases espaciais similares à de Neuquén.

\footnotetext{
${ }^{13}$ República Popular da China
} 
A Estação CLTC-CONAE-NEUQUEN é composta por uma estrutura de 540 toneladas, com área de 200 hectares. $O$ aluguel, pagamento de impostos à China's National Space Agency ${ }^{14}$, isenção de IVA, facilitação aduaneira pelo prazo de cinquenta anos e, ainda, a responsabilização trabalhista e civil dos funcionários chineses do empreendimento seguirão as leis da China e não do solo argentino (URDINEZ et al., 2016), e a Argentina terá acesso a apenas 10\% (dez por cento) dos dados fornecidos pela estação espacial (FREITAS, 2016; WILSON, 2015; URDINEZ et al., 2016). Adicionalmente, a aprovação de lei provincial em 2014 assegura leis migratórias mais benevolentes aos trabalhadores chineses (URDINEZ et al., 2016).

A discussão no que se refere à estação espacial ganhou contornos de debate político no Senado argentino. Seligman (2019) demonstra a preocupação dos senadores no relativo à cessão excessiva de prerrogativas sem que fosse permitido supervisionar o funcionamento da base, ou admitir que sua administração fosse operada exclusivamente por militares do Exército Popular de Libertação. Tem-se ainda, o emprego de cidadãos chineses no empreendimento (GARRISON, 2019), bem como não existe a menção a parcerias com órgãos oficiais argentinos de fomento a intercâmbio educacional.

Seligman (2019) complementa a crítica de Garrison (2019) ao alertar que as declarações de Pequim e Buenos Aires muito embora sinalizem que o uso da estação espacial será civil e pacífico, de fato, será operacionalizada por militares chineses. As reações da comunidade internacional ao avanço chinês encontram eco na seara de nações como EUA e União Europeia, para quem a expansão chinesa é preocupante, visto que os investimentos visam monitorar, espionar e coletar informações dos satélites dos países da aliança atlântica, bem como de sua posição no espaço, pois "a localização

\footnotetext{
${ }^{14}$ Agência Espacial Nacional Chinesa (tradução nossa).
} 
geográfica da nova estação fornece cobertura espacial crítica à China nos hemisférios sul e oeste" (SELIGMAN, 2019).

Esta preocupação tem substrato no acordo firmado em 2015 que, no artigo segundo, trata da cooperação bilateral espacial e em seus incisos preconiza o desenvolvimento de veículos espaciais, bem como estações terrestres visando a recepção, o acompanhamento e atividades de telemetria e, ainda, lançamento de satélites e desenvolvimento de projetos cuja aplicação está direcionada para telecomunicações, navegação e a teleobservação (ARGENTINA, 2020a).

Todavia, a cordialidade e generosidade exaradas por Pequim vão demandar contrapartida de Buenos Aires, para que atenda aos interesses chineses na América Latina com repercussão no mundo. A expansão chinesa necessita de presença junto à comunidade internacional e é nesse sentido que a construção da estação espacial, com posição privilegiada e finalidade pacífica e não militar, precisou ser confirmada em protocolo adicional assinado em setembro de 2016 (VAN DE MAELE, 2017, p. 57). Isso Ihe permitirá, por exemplo, economia para futuras expedições à Lua. Wilson (2015) aduz que a posição estratégica da base permite comunicação em tempo real sem deslocamento de satélites à China, bem como abre possibilidades sobre pesquisas em Marte e sobre eventual envio de missões não tripuladas (WILSON, 2015, p. 4).

Porém, a preocupação das autoridades norte-americanas e europeias nesta manobra se refere à forma como a China pode controlar o rumo dos satélites, influenciando o destino de sua missão. Portanto, entendem que a finalidade desta base é o de espionagem do serviço secreto dos EUA e da União Europeia, pois segundo Van de Maele (2017), o arcabouço da estação espacial envolve instalações de antenas parabólicas direcionáveis que podem atingir até 35 metros de diâmetro, bem como meios necessários à engenharia espacial e de alojamentos para a equipe técnica chinesa. Isto, sem contar a construção de usina elétrica cujo custo 
chega a aproximadamente USD 10 milhões de dólares, o que, segundo Van de Maele (2017), configura terreno propício para guerras cibernéticas no futuro. Agregue-se a isso, o alerta de Arguello (2019) que questiona a magnitude do empreendimento que pode ter uso dual, portanto pacífico e militar mas, ao mesmo tempo, que preconize pesquisas de cunho científico com condições de espionar e interceptar dados.

A Estação CLTC-CONAE-NEUQUEN é parte integrante do novo paradigma chinês de política externa na América Latina. O intuito chinês de cooperação precisa ser enxergado sob a ótica do "win-win"15 e o cuidado com o direcionamento dos investimentos em infraestrutura na região. A justificativa oficial do projeto é o de realizar observação e exploração pacífica do espaço e que já contribuiu com o sucesso da missão no lado escuro da lua. Porém, segundo relato descrito por Urdinez et al (2016), o objetivo primordial da China, a emergir como potência global neste século, está particularmente em desenvolver pesquisas visando a exploração de Marte.

\section{Considerações finais}

Este artigo demonstra a importância do estudo das relações internacionais que envolvam países latino-americanos e de outros continentes do globo, bem como a forma como se relacionam e da maneira que suas decisões podem impactar o cenário regional. $\bigcirc$ trabalho exposto serve como premissa para chamar a atenção da comunidade acadêmica sobre a importância do tema e da necessidade de estudos mais aprofundados, visto que as relações entre nações soberanas são regidas por complexas negociações e com eventual mudança de rumo a depender do incumbente que está no exercício do cargo de chefe de Estado.

\footnotetext{
${ }^{15}$ Ganha-ganha (tradução nossa)
} 
Ficou exposto que no campo das relações internacionais, os motivos que levam os países a celebrarem acordos seguem motivações que atendem interesses de curto prazo, como no caso da Argentina, que precisava do auxílio para poder suportar com mais vitalidade às pressões internas e externas. Por outro lado, este país também enxergava na celebração desse acordo resultados em prazo mais extenso, visto que as informações coletadas sem fins militares poderiam direcionar a ciência e investigações daquele país sobre o espaço.

A reflexão orientada neste trabalho diz respeito a como a entrada da China com o perfil de cooperação e da harmonia a países da América Latina pode ou não ser benéfica a estes países, pois a cessão de soberania que a estação espacial chinesa obriga à Argentina pode criar situações de disputa antes nunca vistas, já que o acordo prevê que Buenos Aires, além de abrir mão da jurisdição que envolve à localidade, terá à disposição apenas 10\% das informações pesquisadas, a título de compartilhamento. Nesse contexto, deve-se pensar na ingerência na soberania nacional e de como ela pode afetar os demais países vizinhos, visto que o poder de Pequim atualmente é superior em termos tecnológicos ao dos países da América Latina.

Digno de nota, a questão a ser investigada no presente artigo diz respeito ao animus do apoio mútuo em questões sensíveis dos dois países e de como esta situação traz disposição para negociar. A dificuldade financeira argentina e a disposição de Pequim em ocupar brechas relegadas pelos norte-americanos no continente auxiliam o êxito do gigante asiático na região. O resultado conduz para maior visibilidade entre as nações e, assim, estes contornos vão se ajustando à sistemática global. Fato é que, indiscutivelmente, a China apresenta condições excepcionais de investimentos em várias frentes e em todos os continentes do globo e, aproveita as brechas para poder efetuar diálogos de alto nível. Contudo, o 
faz de modo a tirar proveito da melhor forma possível visando o seu desenvolvimento interno.

A principal contribuição do presente trabalho aponta na direção de atentarmos para as verdadeiras intenções dos países que buscam celebrar acordos que envolvam as riquezas naturais de outras nações e a exigência de compartilhamento ou cessão de soberania, pois pode-se tentar resolver um problema criando um maior, vez que as regras estipuladas não são facilmente renegociadas quando do outro lado se encontra um ator mais poderoso e não disposto a abrir mão daquilo que fora conquistado.

É importante destacar que em momentos de vulnerabilidade, as nações podem não ter a temperança necessária para celebrar acordos, pois os dirigentes políticos podem estar acossados por problemas internos que necessitam de rápida solução, sob pena de destituição do cargo ou, ainda, de ver diminuídos seus poderes. Desta forma, a negociação pode ser injusta, já que a necessidade imediata o obriga a ceder, quando em momentos de estabilidade não seguiria este caminho.

Os textos e discursos aqui exarados apresentam posições divergentes entre os que defendem a estação espacial e os que alertam para eventuais descaminhos das informações produzidas nesse território. Todavia, se faz cristalina a sobreposição de interesses e como a cooperação harmônica preconizada pela China traz a disputa com os EUA para o solo argentino, deixando a Argentina como mera espectadora desse embate global. Por isso, a intenção do pesquisador em coletar textos com visões pró e contra a China e, consequentemente com os EUA, pois somente com esta multiplicidade se faz possível aprofundar a presente questão.

A crítica, no entanto, estampada por autores que descrevem como perigosa a iniciativa chinesa, costumam demonstrar que a cooperação econômica preconizada por Pequim na verdade esconde um forte componente de alimento político com viés de fazer contraposição com os 
EUA. De modo que a região não será induzida ao desenvolvimento econômico, mas outorgada a esquema de vassalagem e suserania, pois no caso da estação espacial CLTC-CONAE-NEUQUEN, a Argentina renuncia à soberania na área e enxerga que todo o funcionamento do empreendimento funciona com direção chinesa, seja o capital, força de trabalho e tecnologia disponível, ainda que se aplique sua própria legislação, protegendo-se de eventuais questionamentos internos na justiça argentina.

Doravante aos que defendem a instalação da estação espacial, bem como a relação estratégica, enxergam na China a voz com poderio global para defender os interesses da nação, no momento da recuperação econômica e do intercâmbio comercial dual, como também no apoio para a causa das Malvinas. Ou seja, dentro do espectro da harmonia e crescimento conjunto direcionado por Pequim.

No campo da estratégia político-militar, estas lições são fundamentais para a compreensão de fatos que ocorrem na América Latina, em especial na Argentina, e que servem de alerta para estudos mais aprofundados para proporcionar visibilidade à temática no sentido de explanar a futuras gerações sobre fatos presentes que têm repercussão na integração dos países da região.

\section{Referências}

ARANDA, Isabel Rodríguez; VAN DE MAELE, Diego Leiva. El soft power en la política exterior de China: consecuencias para América Latina. Polis. Santiago, v. 12, n. 35, p. 497-517, agosto 2013. Disponível em: https://scielo.conicyt.cl/scielo.php?script=sci_arttext\&pid=\$0718-6568201300 0200022\&lng=es\& $\mathrm{nrm}=$ iso . Acesso em: 6 jan, 2020. http://dx.doi.org/10.4067/S0718-65682013000200022.

ARGENTINA. Presidencia. Ministerio de Relaciones Exteriores, Comercio Internacional y Culto. Acuerdo Marco para la Cooperación en el campo de las actividades espaciales entre el Gobierno de la República Argentina y el Gobierno de la República Popular China. 2020a. Disponível 
em:

https://www.boletinoficial.gob.ar/detalleAviso/primera/233243/20200807.

Acesso em: 29 set. 2020.

ARGENTINA. Presidencia. Ministerio de Relaciones Exteriores, Comercio Internacional y Culto. Reunión de trabajo entre el Secretario Filmus y el Embajador de la República Popular China en la Argentina. Información para la Prensa No: 424/20. 23 dez. 2020. 2020b. Disponível em: https://www.cancilleria.gob.ar/es/actualidad/hoticias/reunion-de-trabajo-ent re-el-secretario-filmus-y-el-embajador-de-la-republica. Acesso em: 26 dez. 2020.

ARGUELLO, Irma. Por qué la base china en Neuquén debería preocuparnos. Infobae. 10 fev. 2019. Disponível em: https://www.infobae.com/opinion/2019/02/10/por-que-la-base-china-en-neu quen-deberia-preocuparnos/. Acesso em: 12 dez. 2019.

BONIFACE, Pascal. La Géopolitique. 3. Ed. Paris: Eyrolles, 2016.

CARVALHO, Rogério do Nascimento. A influência britânica no Atlântico Sul: o caso das ilhas Malvinas. Dissertação. Rio de Janeiro: Escola de Guerra Naval, 2017. $104 \mathrm{f}$.

CHINA (Ministério das Relações Exteriores). Declaración Conjunta entre la República Popular China y la República Argentina. Beijing, 13 julho 2010. Disponível em: https://www.fmprc.gov.cn/esp/wjb/zzjg/ldmzs/gjlb/3453/3454/t717906.shtml. Acesso em: 21 nov. 2019.

CHINA (Ministério das Relações Exteriores). Xi Jinping Se Reúne con el Presidente Argentino Makri . Johannesburgo, 27 julho 2018. Disponível em:

https://www.fmprc.gov.cn/esp/wjb/zzjg/ldmzs/gjlb/3453/3455/t1581093.shtml . Acesso em: 21 nov. 2019.

CHINA. Full text of China's Policy Paper on Latin America and the Caribbean. 242 nov. 2016.2 Disponível em: http://www.china.org.cn/world/2016-11/24/content_39777989.htm. Acesso em: 14 dez. 2019.

COSTA, Wanderley Messias da. Geografia Política e Geopolítica: Discursos sobre o Território e o Poder. $2^{a}$ ed. $3^{a}$ reimpr. São Paulo: Editora da Universidade de São Paulo, 2016.

DINATALE, Martín. Por pedido de Xi Jinping, el Gobierno ratificó el acuerdo con China por la estación espacial en Neuquén. Infobae. 08 agosto 2020. Acesso

em: 
https://www.infobae.com/politica/2020/08/08/por-pedido-de-xi-jinping-el-g obierno-ratifico-el-acuerdo-con-china-por-la-estacion-espacial-en-neuque n/ . Disponível em: 29 set. 2020.

ELLIS, Evan. China's Strategy in Latin America Demonstrates the boldness of President Xi. The Manzella Report. 19 fev. 2014. Disponível em: $<$ https://phibetaiota.net/wp-content/uploads/2014/02/Chinas-Strategy-in-La tin-America-CELAC-Forum.pdf. Acesso em: 29 nov. 2019.

FREITAS, Alexandre de Barros. Relações Argentina - China: a construção de um vínculo assimétrico. Artigo científico. Brasília: Universidade de Brasília, $2016 . \quad 26 \quad$ p. 26 Disponível http://bdm.unb.br/bitstream/10483/17523/1/2016_AlexandredeBarrosFreitas_ tcc.pdf. Acesso em: 02 dez 2019.

GARRISON, Cassandra. Argentine lawmakers seek greater oversight of Chinese space facility in Patagonia. Reuters. 29 março 2019. Disponível em: https://www.reuters.com/article/us-argentina-china-space/argentine-lawma kers-seek-greater-oversight-of-chinese-space-facility-in-patagonia-idUSKC N1RA24I. Acesso em: 07 nov. 2019.

GOMES JÚNIOR, Amaury Marcial. A Geopolítica da China e a sua influência na Argentina: possíveis reflexos para a Marinha do Brasil. Dissertação. Rio de Janeiro: Escola de Guerra Naval, 2016. 130 f.

GOSWAMI, Namrata. China's grand strategy in outer space: to establish compelling standards of behavior. The Space Review. 05 agosto 2019. Disponível em: https://www.thespacereview.com/article/3773/1. Acesso em: 07 nov. 2019.

HANBAN, 2019. Instituto Confucio-Acerca del Instituto/Aula Confucio. Disponível em: http://spanish.hanban.org/confuciousinstitutes/node_31587.htm. Acesso em: 06 jan. 2020.

JAFFE, Alexandra. China built a $\$ 50$ million space base in Argentina to reach the dark side of the moon, but it's casting a shadow on its neighbors. Vice News. 30 nov. 2018. Disponível em: <https://www.vice.com/en_us/article/a3mje4/china-built-a-dollar50-billion-s pace-base-in-argentina-to-reach-the-dark-side-of-the-moon-but-its-castin g-a-shadow-on-its-neighbors. Acesso em: 21 nov. 2019.

LONDOÑO, Ernesto. Desde una estación espacial en Argentina, China expande su presencia en Latinoamérica. América Latina. Negócios. The New York Times (Esp). 28 julho 2018. Disponível em: <https://www.nytimes.com/es/2018/07/28/china-america-latina-argentina>. Acesso em: 21 nov. 2019. 
PARELLO-PLESNER, Jonas. China's risk map in the South Atlantic. Washington: The German Marshall Fund of the United States, 2016. Disponível em: http://www.gmfus.org/listings/research/type/publication. Acesso em: 12 dez. 2019.

SELIGMAN, Lara. U.S. Military Warns of Threat From Chinese-Run Space Station in Argentina. Foreign Policy. 08 fev. 2019. Disponível em: https://foreignpolicy.com/2019/02/08/us-military-warns-of-threat-from-chin ese-run-space-station-in-argentina/. Acesso em: 21 nov. 2019.

SHIXUE, Jiang. Una mirada china a las relaciones con América Latina. Nueva Sociedad. $\mathrm{n}^{\circ} 203$ / maio/junho 2006. p. 62-78. ISSN 0251-3552. Disponível em: https://dialnet.unirioja.es/servlet/articulo?codigo=2380771. Acesso em: 21 nov. 2019.

URDINEZ, Francisco; KNOERICH, Jan; RIBEIRO, Pedro Feliú. Don't Cry for Me 'Argenchina': Unraveling Political Views of China Through Legislative Debates in Argentina. Journal of Chinese Political Science. 9 maio 2016. Disponível em: https://ssrn.com/abstract=2782054. Acesso em: 24 dez. 2019. http://dx.doi.org/10.2139/ssrn.2782054

VAN DE MAELE, Diego Leiva. Xi Jinping and The Sino - Latin American Relations in The 21st Century: Facing The Beginning of A New Phase? The Journal of China and International Relations. Vol 5 No 1, 2017. Disponível em: https://journals.aau.dk/index.php/jcir/article/view/1916/1481. Acesso em: 02 jan. 2020.

DOI: https://doi.org/10.5278/ojs.jcir.v5i1.1916

WILSON, Jordan. China's Military Agreements with Argentina: A Potential New Phase in China-Latin America Defense Relations. Staff Research Report. U.S.-China Economic and Security Review Commission. 2015. Disponível em: https://www.uscc.gov/sites/default/files/Research/China's\%20Military\%20Agr eements\%20with\%20Argentina.pdf . Acesso em: 19 nov. 2019. 